\title{
Oct4B, CD90, and CD73 are upregulated in bladder tissue following electro-resection of the bladder
}

\author{
Takeuchi $\mathrm{T}^{1}$, Tonooka $\mathrm{A}^{2}$, Okuno $\mathrm{Y}^{1}$, Hattori-Kato $\mathrm{M}^{1}$, Mikami $\mathrm{K}^{1}$
}

Aim: We tested the hypothesis that stimulation by electro-resection of bladder tissue induces stem cells in the tissue repair process. Materials \& Methods: After primary transurethral resection of a bladder tumor and surrounding tissue (TUR-Bt), second TUR-Bt was performed. Tissues excised by second TUR-Bt were immunohistochemically stained for Oct4, a marker of pluripotency, and for CD90 and CD73, markers of mesenchymal stromal cells, when no bladder tumor cells remained. Results and Conclusions: Oct4B protein was sporadically stained in the cytoplasm of interstitial cells in four out of eight cases. CD90 and CD73 are upregulated in interstitial and vascular endothelial cells without CD45 expression. Mesenchymal stromal cells, but not pluripotent stem cells, may be mainly involved in bladder tissue repair.

Key Words: Oct4B, CD90, CD73, Electric, Stimulation, Bladder

\section{Introduction}

In 2014, Obokata et al., reported a cellular reprogramming phenomenon with acid treatment called stimulus-triggered acquisition of pluripotency (STAP). Unfortunately, their article was retracted because of misconduct, and the trial to replicate of the STAP cell phenomenon by other groups failed ${ }^{[1]}$. Nevertheless, the idea that strong environmental stimuli may reprogram differentiated somatic cells into less-differentiated ones is still worth pursuing.

The POU family transcription factor Oct4 (octamer-binding transcription factor 4) is an essential regulator of pluripotency and is of central significance in nuclear reprogramming ${ }^{[2]}$. It is one of the four reprogramming Yamanaka factors generating induced pluripotent stem cells ${ }^{[3]}$. Mesenchymal stromal cells (MSCs) are a rare population of non-hematopoietic stromal cells that reside in the bone marrow and connective tissues. They have the potential to differentiate into mesenchymal tissues such as bone, cartilage, muscle, and adipose tissues and, therefore, can be significant in tissue repair ${ }^{[4]}$. CD90 (thymus cell antigen 1) and CD73 (ecto-5'nucleotidase) are surrogate positive markers of MSCs, while MSCs lack CD45 (leukocyte common antigen) expression ${ }^{[5,6]}$.

Transurethral electro-resection of intravesical tumors (TUR-Bt) is the first step in the treatment of bladder cancer. To confirm the completeness of endoscopic resection of bladder tumors, secondary resection of bladder tissue at the site of the preceding resection is performed within a few months. When no tumors remain in the resected specimens, the bladder is often preserved in situ. In the patients, the bladder tissue after primary electro-resection undergoes tissue repair. We hypothesized that the STAP phenomenon can be introduced by the stimulus of electro-resection in the bladder tissue during regeneration and that various levels of stem cell markers such as Oct4, CD90, and CD73 would appear in the bladder tissue resected by the secondary electro-resection.

\section{Materials and Methods}

Following endoscopic primary bipolar electro-resection of bladder tumors in saline (the TURis system, Olympus, Tokyo, Japan), secondary resection of bladder tissue at the primary resection site was performed. Those electro-resections were done at 280 watts.

Eight bladder paraffin-embedded specimens of secondary resections without remaining bladder tumors on examination with hematoxylineosin staining were immunohistochemically stained using anti-human Oct4 rabbit monoclonal antibody raised against amino acids 250-350 of human origin (EPR2054, Abcam, Cambridge, UK), anti-human Oct4 mouse monoclonal antibody raised against amino acids 1-134 of human origin (sc-5279, Santa Cruz Biothchnology, Inc., Dallas, Texas, USA), anti-human CD90/Thy1 rabbit monoclonal antibody (EPR3132, Abcam, Cambridge, UK), anti-human CD73 mouse monoclonal antibody (sc-32299, Santa Cruz Biotchnology, Inc., Dallas, Texas, USA), and anti-human CD45 mouse monoclonal antibody (IR751, Dako Japan, Tokyo, Japan). The mean interval between the primary and secondary electro-resection for the eight patients was 58 days. EPR2054 antibody detects both Oct4A and Oct4B proteins, while sc-5279 identifies Oct4A protein only.

The pathological diagnoses of corresponding primary tumors were all urothelial cancer and those specimens were also stained for Oct 4 and CD90 as above. Two paraffin-embedded specimens of bladders excised at autopsy (died of cardiac infarction and pancreatic cancer), two paraffin-embedded specimens of testicular embryonal cancers, and paraffin-embedded specimens of primary TUR-Bts were similarly stained. 


\section{Results}

As summarized in Table 1, the pT stages of primary electro-resection were pT1 or possibly more than pT1, and tumor grades were G2 to G3 in the eight cases with no tumors in the secondary electro-resected specimens. Both EPR2054 and sc-5279 detected Oct4-expressing cells in the nucleus of embryonal cell cancer cells (Figure 1). DAPI staining for nuclear co-localization of Oct4A was not performed. Control autopsy bladder tissues did not show Oct4-expressing cells at all (Figure 2) by either EPR2054 or sc-5279. In four out of the eight cases, Oct4 protein was sporadically stained with EPR2054 in the cytoplasm of interstitial cells located in the specimens of second TUR-Bt (Figure 3 and Figure 4), but sc-5279 did not detect Oct4A protein in the specimens, revealing that Oct 4 detected by EPR2054 is Oct4B. In bladder tumors resected by the primary TUR-Bt, Oct4A was not detected by sc-5279. Oct4 was sporadically demonstrated in five out of the eight bladder tumors in the cytoplasm of interstitial cells, but not in tumor cells by EPR2054, showing that the detected Oct4 was Oct4B (Data not shown).
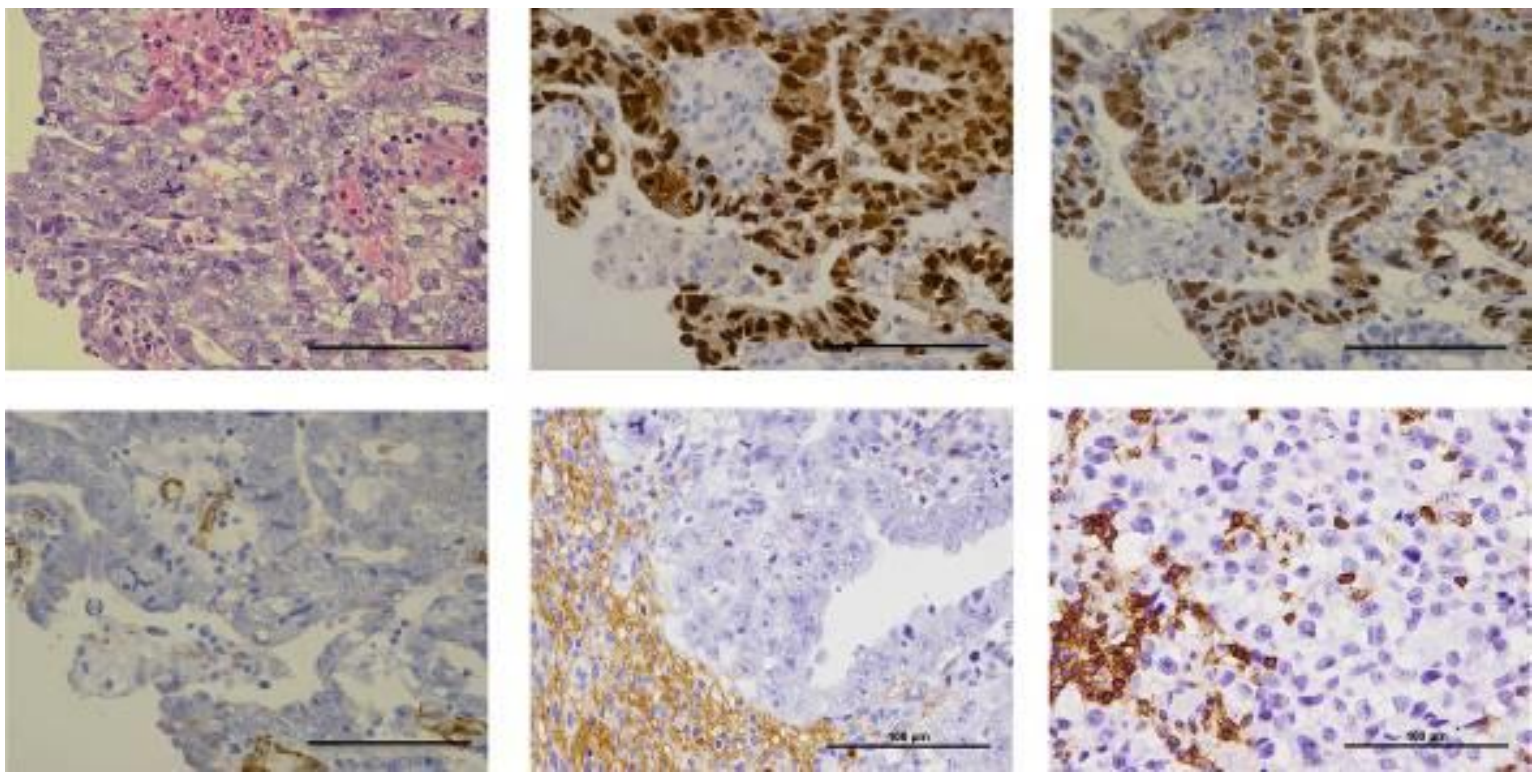

Figure 1: Immunohistochemistry of embryonal cell cancer. Upper left: hematoxylin and eosin staining. Upper middle: Oct4 staining with EPR2054. Upper right: Oct4A staining with sc-5279. Lower left: CD90 staining. Lower middle: CD73 staining. Lower right: CD45 staining. $400 x$ in the original picture, and Bar=100 $\mu$ m. Oct4A was expressed in the nucleus of embryonal cell cancer cells. CD90 was weakly positive in the vascular endothelial cells. CD73 was negative in embryonal cell cancer, while CD45 was expressed in lymphocytes infiltrating cancer. In the stroma surrounding embryonal cell carcinomas, CD73 was strongly positive.
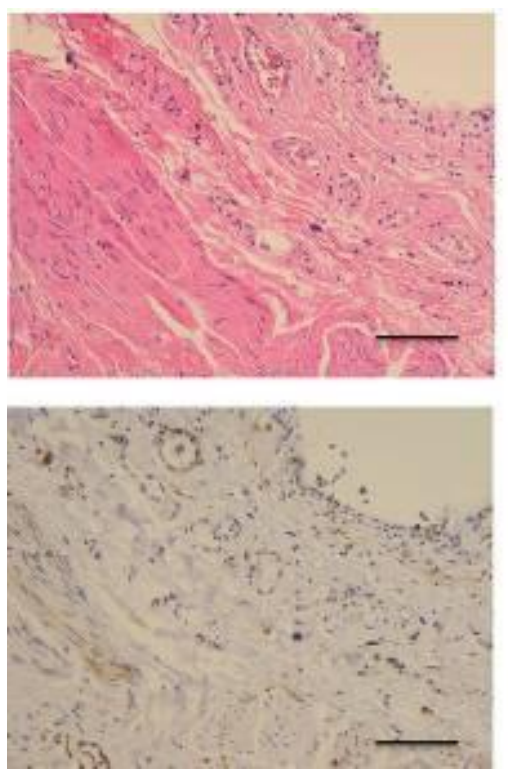
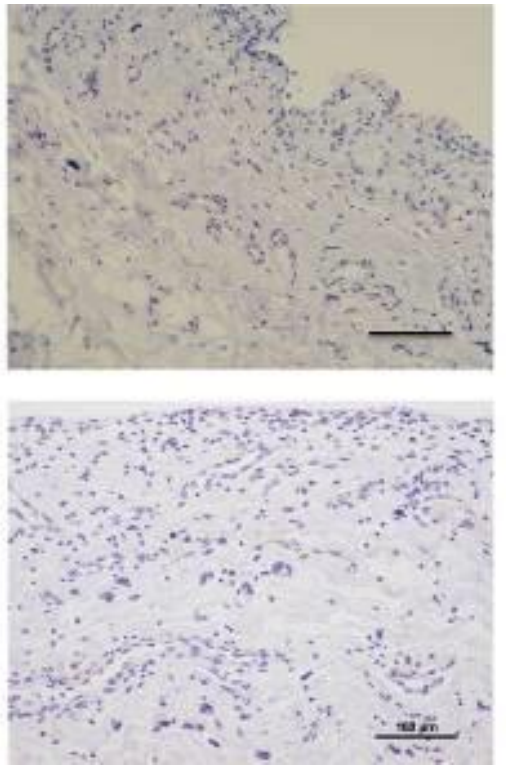
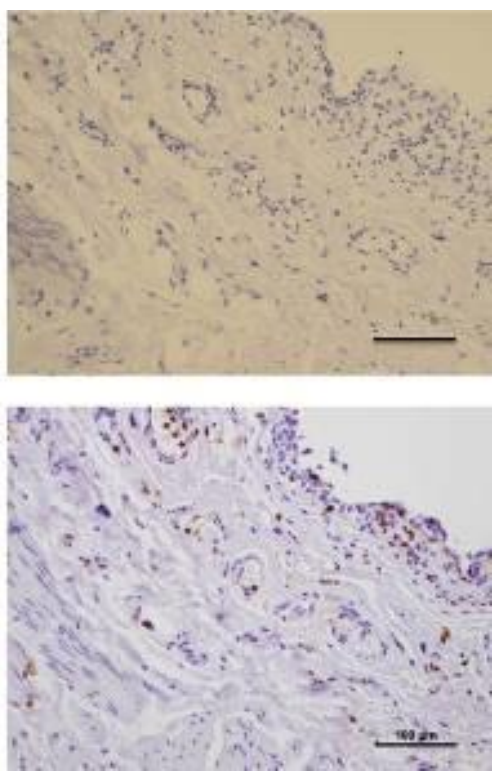

Figure 2: Immunohistochemistry of representative (died of cardiac infarction) control autopsy bladder tissue. Upper left: hematoxylin and eosin staining. Upper middle: Oct4 staining with EPR2054. Upper right: Oct4A staining with sc-5279. Lower left: CD90 staining. Lower middle: CD73 staining. Lower right: CD45 staining. $200 x$ in the original picture, and Bar $=100 \mu \mathrm{m}$. Oct4A, Oct4B, and CD73 were negative. CD90 was weakly positive in the vascular endothelial cells. CD45 was expressed in lymphocytes. 

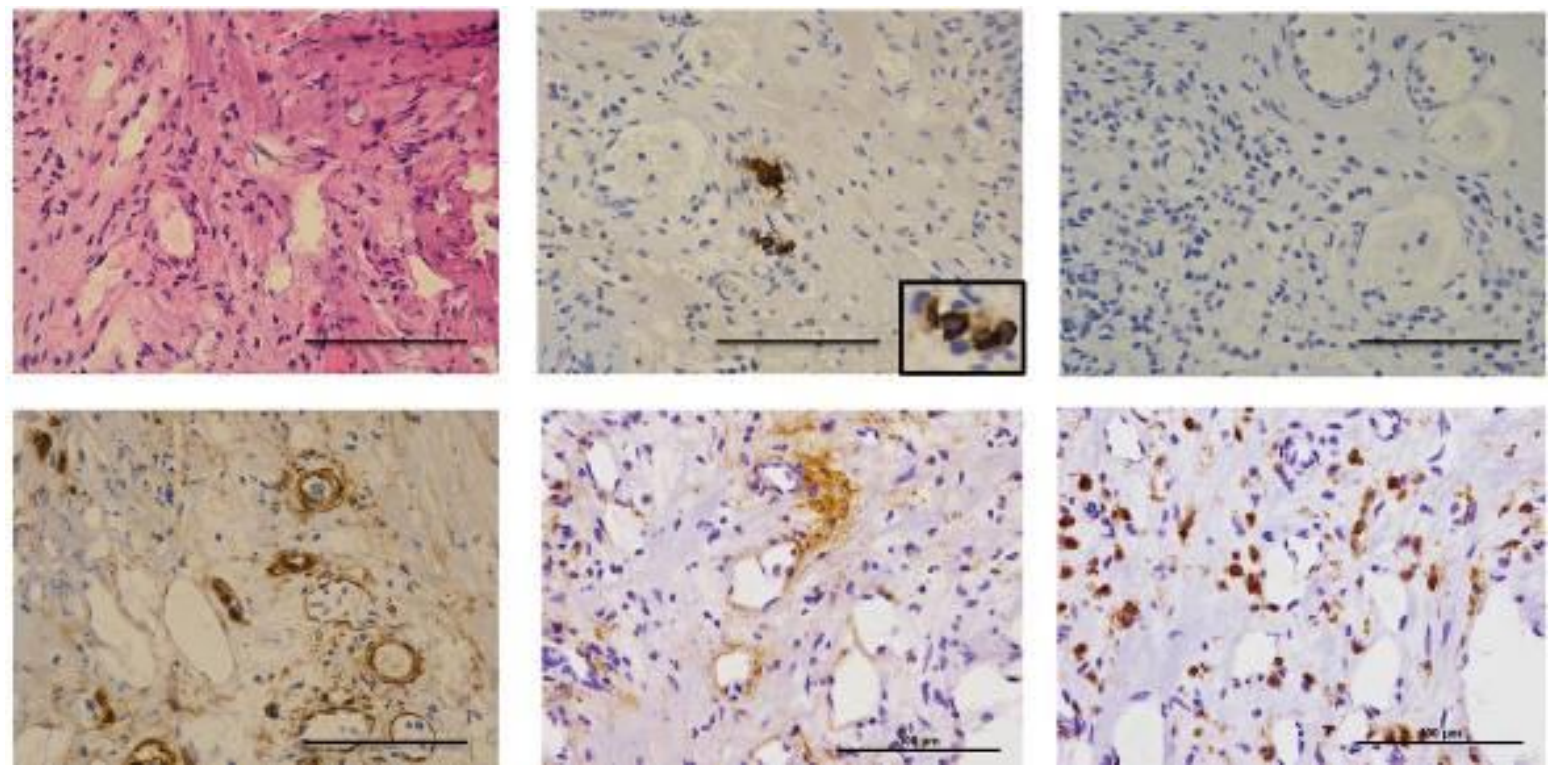

Figure 3: Immunohistochemistry of a representative specimen of second TUR-Bt. Upper left: hematoxylin and eosin staining. Upper middle: Oct4 (Oct4B) staining with EPR2054 (a portion of positive cells is magnified at the corner). Upper right: Oct4A staining with sc-5279. Lower left: CD90 staining. Lower middle: CD73 staining. Lower right: CD45 staining. $400 x$ in the original picture, and Bar $=100 \mu \mathrm{m}$. Oct $4 B$ was expressed in the cytoplasm of interstitial cells. Oct $4 A$ was negative. CD90 and CD73 were expressed in the interstitial and vascular endothelial cells. CD45 was expressed in lymphocytes infiltrating tissue.
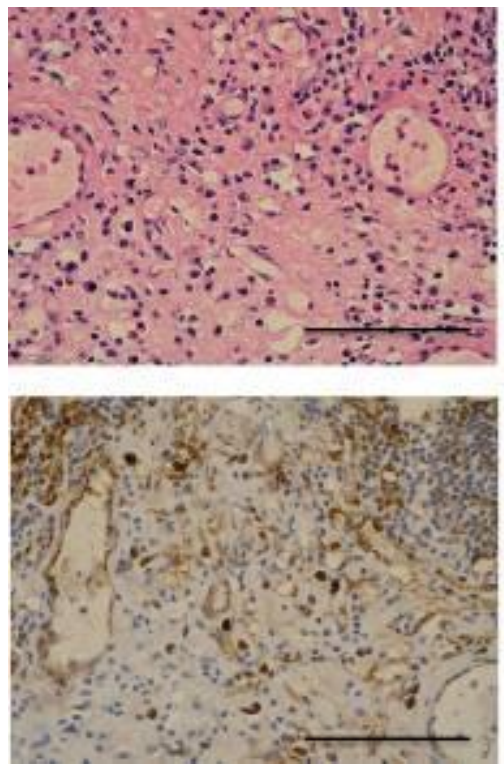
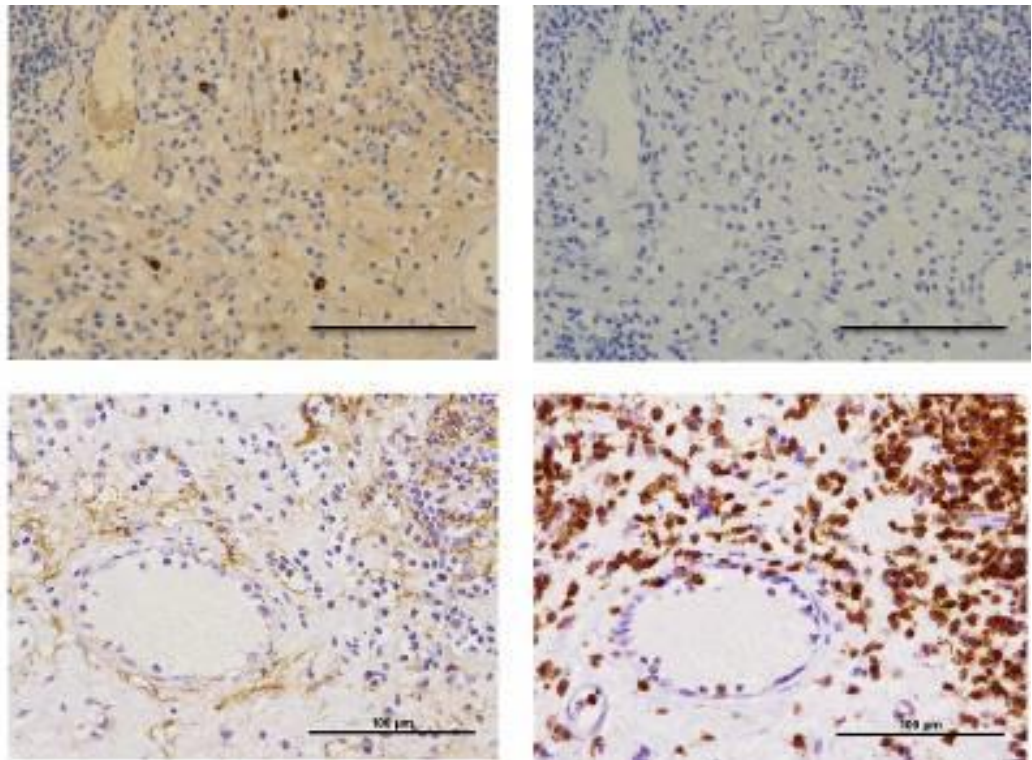

Figure 4: Immunohistochemistry of a representative specimen of second TUR-Bt. Upper left: hematoxylin and eosin staining. Upper middle: Oct4 (Oct4B) staining with EPR2054. Upper right: Oct4A staining with sc-5279. Lower left: CD90 staining. Lower middle: CD73 staining. Lower right: CD45 staining. $400 x$ in the original picture, and Bar $=100 \mu \mathrm{m}$. Oct $4 B$ was expressed in the cytoplasm of interstitial cells. Oct4A was negative. CD90 and CD73 were expressed in the interstitial and vascular endothelial cells. CD45 was expressed in lymphocytes infiltrating tissue.

CD90 expression was weakly positive in the vascular endothelial cells and CD73 was basically negative in control autopsy bladders and embryonal cell carcinomas, while CD45 was detected in lymphocytes there. In the stroma surrounding embryonal cell carcinomas, CD73 was strongly positive. CD90 and CD73 were markedly up-regulated in the interstitial cells in addition to showing enhanced expression in vascular endothelial cells in all electro-resected specimens by the second TUR-Bt ( $\mathrm{p}=0.0016$ by the chi-square test, compared with autopsy controls). CD45 was not detected in either interstitial or endothelial cells, being expressed only in lymphocytes infiltrating the electro-resected specimens. In bladder tumors resected by the primary TUR-Bt, CD90 was stained in vascular endothelial and interstitial cells, and possibly smooth muscle cells (Data not shown).

The clinical courses after second TUR-Bt are listed in Table 1. Six patients underwent BCG bladder instillation as an adjuvant therapy. Intravesical tumor recurrence occurred in one case. One case has shown no tumor recurrence without additional therapy since second TUR-Bt and another has undergone total cystectomy without any remaining tumor in the cystectomy specimen. 
Table 1

\begin{tabular}{|c|c|c|c|c|c|c|c|c|c|}
\hline Patient & Age & $\begin{array}{c}\text { Pathology of 1 1t } \\
\text { TUR-BT }\end{array}$ & Intervals & Oct4B & Oct4A & CD90 & CD73 & CD45 & Clinical course after 2 \\
\hline 1 & 72 & $\mathrm{UC}, \mathrm{pT} 1 \leqq, \mathrm{G} 2>\mathrm{G} 3$ & 35 & + & - & + & + & - & $\begin{array}{c}\text { No remaining tumor in Cx } \\
\text { specimen, }\end{array}$ \\
\hline 2 & 77 & $\mathrm{UC}, \mathrm{pT} 1, \mathrm{G} 3$ & 80 & + & - & + & + & - & $\begin{array}{c}\text { No bladder recurrence for } \\
1,103 \text { days }\end{array}$ \\
\hline 3 & 65 & $\mathrm{UC}, \mathrm{pT} 1 \leqq, \mathrm{G} 3>\mathrm{G} 2$ & 59 & - & - & + & + & - & $\begin{array}{c}\text { BCG+, no bladder recurrence for } \\
1,069 \text { days }\end{array}$ \\
\hline 4 & 69 & $\mathrm{UC}, \mathrm{pT} 1, \mathrm{G} 2>\mathrm{G} 3$ & 73 & - & - & + & + & - & $\begin{array}{c}\text { BCG+, no bladder recurrence for } \\
939 \text { days }\end{array}$ \\
\hline 5 & 63 & $\mathrm{UC}, \mathrm{pT} 1 \leqq, \mathrm{G} 2>\mathrm{G} 3$ & 63 & - & - & + & + & - & $\begin{array}{c}\text { BCG+, no bladder recurrence for } \\
838 \text { days }\end{array}$ \\
\hline 6 & 54 & $\mathrm{UC}, \mathrm{pT} 1, \mathrm{G} 2$ & 56 & + & - & + & + & - & $\begin{array}{c}\text { BCG+, no bladder recurrence for } \\
659 \text { days }\end{array}$ \\
\hline 7 & 76 & $\mathrm{UC}, \mathrm{pT} 1, \mathrm{G} 2>\mathrm{G} 3$ & 56 & - & - & + & + & - & $\begin{array}{c}\text { BCG+, no bladder recurrence for } \\
544 \text { days }\end{array}$ \\
\hline 8 & 81 & $\mathrm{UC}, \mathrm{pT} 1, \mathrm{G} 2>\mathrm{G} 3$ & 42 & + & - & + & + & - & $\begin{array}{c}\text { BCG+, CIS after } \\
600 \text { days }\end{array}$ \\
\hline
\end{tabular}

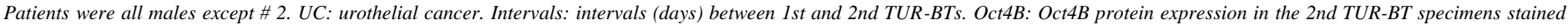

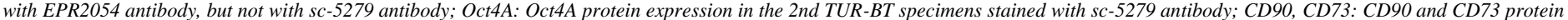

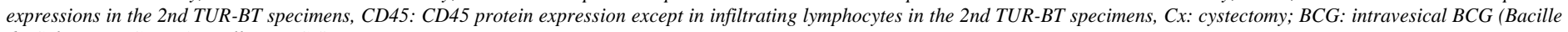
de Calmette et Guérin) instillation, CIS: carcinoma in situ.

\section{Discussion}

In the present study, Oct4-positive cells were observed in electrostimulated bladder tissue. However, it is important to identify which isoform of Oct4 is expressed and to take the function of expressed Oct4 into consideration. There are three splice variants of Oct4: Oct4A, Oct4B, and Oct4B1, caused by alternative splicing of Pou5f1 mRNA. Oct4B mRNA produces three isoforms: Oct4B-164, Oct4B190 , and Oct4B-265, by alternative translation ${ }^{[7]}$. Only Oct4A has been shown to be a definite marker of pluripotency and self-renewal of cells.

In applying immunohistochemistry to specimens, an antibody against exon 1a of the Oct 4 gene uniquely stains Oct $4 \mathrm{~A}$ protein, but not Oct4B and Oct4B1 isoforms because Oct4B and Oct4B1 mRNAs are missing exon $1 \mathrm{a}^{[8]}$. Additionally, Oct $4 \mathrm{~A}$ is generally located in the nucleus, while Oct4B and Oct4B1 are in the cytoplasm ${ }^{[9-11]}$. In our study, Oct4 protein expression was detected in the cytoplasm with EPR3132 antibody against exons 4-5, but not with that against exon 1a (sc-5279). This indicates that Oct4B-positive cells appeared in the tissue following electro-resection of the bladder. EPR3112 will not detect Oct4B1, as the Oct4B1 protein is truncated due to the stop codon TGA located in exon $2 b$ harbored as a cryptic exon ${ }^{[12]}$.

The functions of Oct4B and Oct4B1 are basically unknown. Oct4B has been reported to be expressed in the cytoplasm of various tumor cells ${ }^{[13-15]}$. It increases with tumor proliferation and angiogenesis, and protects tumors from apoptosis ${ }^{[16-18]}$. Oct4B1 was originally regarded as a putative marker of stemness ${ }^{[12,19]}$ and is expressed in human colorectal cancer ${ }^{[20]}$. Additionally, two isoforms of OCT4B, OCT4B190 and OCT4B-265, as well as Oct4B1 have been reported to be upregulated in response to various kinds of stress ${ }^{[7,11,21]}$. Electroresection of bladder tissue and the subsequent reactions in the present study may have caused the stress-triggered appearance/infiltration of Oct4B protein-expressing cells.

CD90 and CD73, markers of MSCs, were enhanced in the tissue resected by the second TUR-Bt, while CD45 expression was limited to infiltrating lymphocytes. Then, electric stimulation administered to the bladder tissue in the primary TUR-Bt may have induced the recruitment and activation of MSCs that participate in the repair of bladder tissues. CD90 has been reported to be overexpressed in activated tumor endothelial cells compared with normal endothelial cells $^{[22,23]}$. Vascular endothelial cells in the regenerating tissue may be similar to tumor endothelial cells.

\section{Conclusion}

Electro-resection of bladder tissue induced the appearance of Oct4B protein-expressing interstitial cells as well as enhanced CD90 and CD73 expression in the vascular endothelial and interstitial cells. Not pluripotent stem cells, but the more downstream MSCs may be mainly involved in tissue repair of the bladder. 


\section{References}

1. De Los Angeles A, Ferrari F, Fujiwara Y, Mathieu R, Lee S, Lee S, Tu HC, Ross S, Chou S, Nguyen M, Wu Z, Theunissen TW, Powell BE, Imsoonthornruksa S, Chen J, Borkent M, Krupalnik V, Lujan E, Wernig M, Hanna JH, Hochedlinger K, Pei D, Jaenisch R, Deng H, Orkin SH, Park PJ, Daley GQ. Failure to replicate the STAP cell phenomenon. Nature. 2015; 525(7570): E6-9.

2. Radzisheuskaya A, Silva JC. Do all roads lead to Oct4? The emerging concepts of induced pluripotency. Trends Cell Biol. 2014; 24(5): 275-284.

3. Takahashi K, Yamanaka S. Induction of pluripotent stem cells from mouse embryonic and adult fibroblast cultures by defined factors. Cell. 2006; 126(4): 663-676.

4. Augello A, Kurth TB, De Bari C. Mesenchymal stem cells: a perspective from in vitro cultures to in vivo migration and niches. Eur Cell Mater. 2010; 20: 121-133.

5. Barda-Saad M, Rozenszajn LA, Ashush H, Shav-Tal Y, Ben Nun A, Zipori D. Adhesion molecules involved in the interactions between early $\mathrm{T}$ cells and mesenchymal bone marrow stromal cells. Exp Hematol. 1999; 27(5): 834844.

6. Barry F, Boynton R, Murphy M, Haynesworth S, Zaia J. The SH-3 and SH-4 antibodies recognize distinct epitopes on CD73 from human mesenchymal stem cells. Biochem Biophys Res Commun. 2001; 289(2): 519-524.

7. Gao Y, Wei J, Han J, Wang X, Su G, Zhao Y, Chen B, Xiao Z, Cao J, Dai J. The novel function of OCT4B isoform-265 in genotoxic stress. Stem Cells. 2012; 30(4): 665-672.

8. Liedtke S, Stephan M, Kögler G. Oct4 expression revisited: potential pitfalls for data misinterpretation in stem cell research. Biol Chem. 2008; 389(7): 845-850.

9. Cauffman G, Van de Velde H, Liebaers I, Van Steirteghem A. Oct-4 mRNA and protein expression during human preimplantation development. Mol Hum Reprod. 2005; 11(3): 173-181.

10. Lee J, Kim HK, Rho JY, Han YM, Kim J. The human OCT-4 isoforms differ in their ability to confer self renewal. J Biol Chem. 2006; 281(44): 33554-33565.

11. Farashahi-Yazd E, Rafiee MR, Soleimani M, Tavallaei M, Salmani MK, Mowla SJ. OCT4B1, a novel spliced variant of OCT4, generates a stable truncated protein with a potential role in stress response. Cancer Lett. 2011; 309(2): 170-175.

12. Gao Y, Wang X, Han J, Xiao Z, Chen B, Su G, Dai J. The novel OCT4 spliced variant OCT4B1 can generate three protein isoforms by alternative splicing into OCT4B. J Genet Genomics. 2010; 37(7): 461-465.

13. Alexander RE, Cheng L, Grignon DJ, Idrees MT. Cytoplasmic OCT4 staining is a sensitive marker of neuroendocrine differentiation. Hum Pathol. 2014; 45(1): 27-32.

14. Di J, Duiveman-de Boer T, Zusterzeel PL, Figdor CG, Massuger LF, Torensma R. The stem cell markers Oct4A, Nanog and c-Myc are expressed in ascites cells and tumor tissue of ovarian cancer patients. Cell Oncol. (Dordr). 2013; 36(5): 363-374.

15. Alexander RE, Cheng L, Grignon DJ, Idrees $M$. Cytoplasmic staining of OCT4 is a highly sensitive marker of adrenal medullary-derived tissue. Am. J Surg Pathol. 2-13; 37(5): 727-733.

16. Cortes-Dericks L, Yazd EF, Mowla SJ, Schmid RA, Karoubi G. Suppression of OCT4B enhances sensitivity of lung adenocarcinoma A549 cells to cisplatin via increased apoptosis. Anticancer Res. 2013; 33(12): 53655373.

17. Li SW, Wu XL, Dong CL, Xie XY, Wu JF, Zhang X. The differential expression of OCT4 isoforms in cervical carcinoma. PLoS One. 2015; 10(3): e0118033.

18. Asadi MH, Mowla SJ, Fathi F, Aleyasin A, Asadzadeh J, Atlasi Y. OCT4B1, a novel spliced variant of OCT4, is highly expressed in gastric cancer and acts as an antiapoptotic factor. Int J Cancer. 2011; 128(11): 26452652.

19. Papamichos SI, Kotoula V, Tarlatzis BC, Agorastos T, Papazisis K, Lambropoulos AF. OCT4B1 isoform: the novel OCT4 alternative spliced variant as a putative marker of stemness. Mol Hum Reprod. 2009; 15(5): 269270.

20. Gazouli M, Roubelakis MG, Theodoropoulos GE, Papailiou J, Vaiopoulou A, Pappa KI, Nikiteas N, Anagnou NP. OCT4 spliced variant OCT4B1 is expressed in human colorectal cancer. Mol Carcinog. 2012; 51(2): 165-173

21. Wang X, Zhao Y, Xiao Z, Chen B, Wei Z, Wang B, Zhang J, Han J, Gao Y, Li L, Zhao H, Zhao W, Lin H, Dai J. Alternative translation of OCT4 by an internal ribosome entry site and its novel function in stress response. Stem Cells. 2009; 27(6): 1265-1275.

22. Ohmura-Kakutani H, Akiyama K, Maishi N, Ohga N, Hida Y, Kawamoto T, lida J, Shindoh M, Tsuchiya K, Shinohara N, Hida K. Identification of tumor endothelial cells with high aldehyde dehydrogenase activity and a highly angiogenic phenotype. PLoS One. 2014; 9(12): e113910.

23. Schubert K, Gutknecht D, Köberle M, Anderegg U, Saalbach A. Melanoma cells use Thy-1 (CD90) on endothelial cells for metastasis formation. Am J Pathol. 2013; 182(1): 266-76.

\begin{abstract}
Abbreviations
STAP : Stimulus-triggered Acquisition of Pluripotency

MSC : Mesenchymal Stromal Cells

TUR-Bt : Transurethral electro-resection of intravesical tumors

BCG : Bacille de Calmette et Guérin
\end{abstract}


Takeuchi T, et al. J Stem Cells Regen Med 2016; 12(1)

\section{Potential Conflicts of Interests}

\section{None}

\section{Ethical standards}

The experiment was conducted with the human subjects' understanding and consent. The Ethical Committee of Kanto Rosai Hospital approved the experiments.

\section{Acknowledgements}

This study was supported by a grant-in-aid for scientific research proposed by Kanto Rosai Hospital.

\section{Corresponding Author}

Takumi Takeuchi, Department of Urology, Kanto Rosai Hospital, 1-1 Kizukisumiyoshi-cho, Nakahara-ku, Kawasaki, Japan. 211-8510; Tel: +81-44-411-3131, Fax : +81-44-433-3150; E-mail address: takeuchit@abelia.ocn.ne.jp 